\title{
Temperature Field Simulation of Laser Drilling in ANSYS
}

\author{
Song Linsen \\ School of Mechanical and Electrical Engineering \\ ChangChun University of Science and Technology \\ ChangChun ,China \\ sls_ciom@126.com
}

\author{
Shi Guoquan \\ School of Mechanical and Electrical Engineering \\ ChangChun University of Science and Technology \\ ChangChun ,China \\ sgq@cust.edu.cn
}

\begin{abstract}
Due to the complexity of the laser and material interaction, it is difficult to control the quality of the hole in the laser drilling process. The thermodynamic model of laser drilling is built which is based on the characteristics of the laser drilling and processing environment. The temperature field of laser drilling is simulated by using the finite element analysis software ANSYS. Through the research on the temperature filed distribution law, different drilling parameters on the effect of the hole quality are analyzed and predicted, which provides a basis for selecting the optimal parameters of the laser drilling.
\end{abstract}

Keyword-laser; drilling; temperature field; simulation; ANSYS

\section{INTRODUCTION}

Laser drilling is the first laser processing technology to achieve the practical usage which is widely used in the field of micro-hole machining ${ }^{[1]}$. However, due to the complexity of laser interaction with material, the drilling parameters mostly rely on the tests. This kind of technology is unable to meet the rapid development of new technology in terms of drilling efficiency and quality ${ }^{[2]}$.

ANSYS is a large common finite element analysis software gathered with structural, thermal, fluid, electromagnetic, acoustics in which is widely used in mechanical manufacturing, aerospace, electronics, civil engineering, water, petrochemical, light industry and many industrial areas. It can solve the problems of steady state, transient, linear and nonlinear heat conduction $^{[3]}$. In this paper, the temperature field with the actual process of laser drilling is simulated and calculated by using the second development language APDL of ANSYS. It laid the technological foundation for the optimal selection of the laser drilling parameters which guaranteed the quality and reduced test costs.

\section{THE MATHEMATICAL MODEL OF LASER DRILLING}

The assumptions in the calculation process are taken as follows ${ }^{[4]}$ :

1) The thermal physical parameters of the material are constant;
2) The laser beam in space is the distribution of the fundamental mode Gaussian;

3) It should be ignored the melting phenomenon in the drilling process and considered only the gasification of the material;

4) Comparing with the laser beam, the smoke produced during the drilling process is very transparent.

Assumption 1) is only for the purpose to simplify the calculation. Drilling with the laser power density formula can be drawn by Assumption 2) as follows:

$$
I(x)=I_{0} \cdot \exp \left(-(0.6 x / R)^{2}\right)
$$

Formula: R-beam radius, - the radius of the spot of the surface of the beam irradiation, - spot the peak power density.

It is mainly considered that the liquid layer formed during laser drilling process is very thin by assumption 3) and the latent heat of vaporization is greater than the melting heat. When calculating the beam energy through the energy conversion in the drilling surface, melting does not have a significant impact on the overall energy balance. It is only to simplify the calculation of the beam energy during the energy conversion process by assumption 4).

Based on the features of the fundamental mode of Gaussian beam in spatial distribution, the drilling sample is disassembled from the spot center during the actual drilling process. A two dimensional nonlinear transient heat balance equation is established which descript the laser drilling process $^{[5]}$.

$$
\rho c \frac{\partial T(x, y, t)}{\partial t}=\left[\lambda \frac{\partial^{2} T(x, y, t)}{\partial x^{2}}\right.
$$

Formula : $\lambda$-Thermal conductivity, $\rho$-density, $c$ Specific heat capacity.

Initial conditions:

$T(x, y, 0)=T_{0}$

Formula: $T_{0}$ - Ambient temperature. 
Boundary conditions:

1) Phase change interface:

$$
\lambda \frac{\partial T(x, y, t)}{\partial z}=-\left[a I(x)-\rho L_{v} v_{r}\right]
$$

Formula : $\lambda$-Thermal conductivity, $a$ - Material absorption coefficient, $L_{V}$ - Latent heat of vaporization, $v_{r}$ Phase change interface of the mobile speed , $v_{r}=I_{0} / \rho\left(L_{V}+c T_{V}\right), T_{V}$ - Vaporization temperature.

2) Sample of peripheral interfaces:

$$
-\lambda \frac{\partial T}{\partial n}=h\left(T-T_{0}\right)+e \sigma\left(T^{4}-T_{0}^{4}\right)
$$

Formula: $\frac{\partial T}{\partial n}$ - The rate of change of temperature along the sample outside the normal, $h$ - Convective heat transfer coefficient, $e$ - Sample surface emission coefficient, $\sigma$ Blackbody radiation constant.

\section{RESULTS AND ANALYSIS}

In this paper, the simulation of temperature field of laser drilling in terms of stainless steel 1Cr18Ni9Ti has been done in ANSYS. The thermal parameters of 1Cr18Ni9Ti have been shown in Table 1.The flow diagram of laser drilling simulation process is shown in Figure 1. In order to do comparative analysis, two sets of laser drilling parameters have been defined as shown in Table 2.

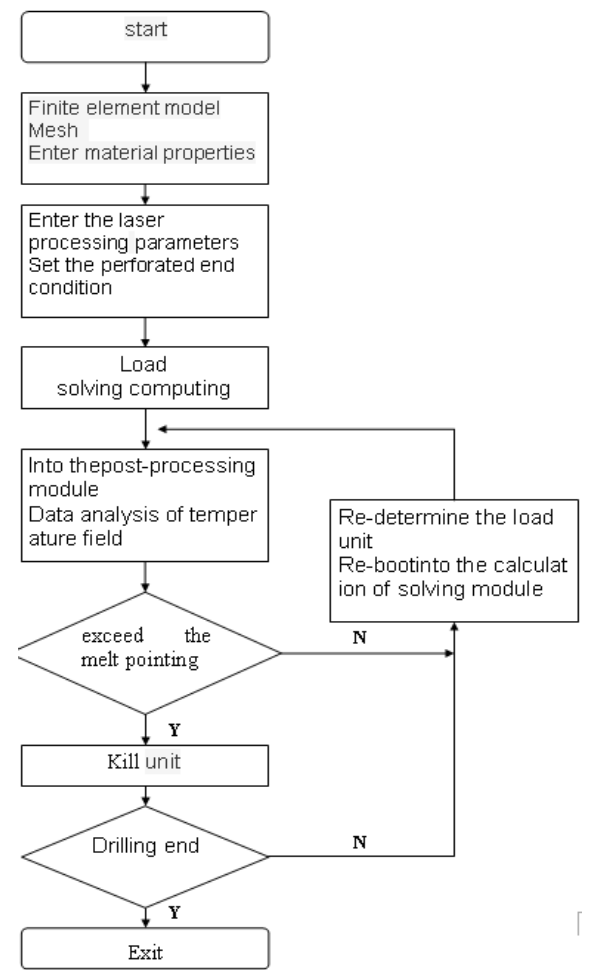

Figure1. The flow diagram of laser drilling simulation process

\begin{tabular}{|c|c|c|c|c|}
\hline Temperature & $\mathbf{0}$ & 1533 & 1595 & 1670 \\
\hline $\begin{array}{c}\text { Heat transfer } \\
\text { coefficient } W /(m \text {. } \\
\left.{ }^{\circ} \mathrm{C}\right)\end{array}$ & 28.2 & 31.2 & 24.4 & 24.4 \\
\hline $\begin{array}{c}\text { Enthalpy value } \\
\mathrm{J} / \mathrm{m}^{3}\end{array}$ & $\mathbf{0}$ & 7.5e9 & $9.6 \mathrm{e} 9$ & 1.05 e10 \\
\hline density $\mathrm{kg} / \mathrm{m}^{3}$ & \multicolumn{4}{|c|}{7800} \\
\hline $\begin{array}{l}\text { the melting } \\
\text { point: }{ }^{\circ} \mathrm{C}\end{array}$ & \multicolumn{4}{|c|}{$1398 \sim 1420$} \\
\hline $\begin{array}{l}\text { the boiling } \\
\text { point: }{ }^{\circ} \mathrm{C}\end{array}$ & \multicolumn{4}{|c|}{2700} \\
\hline $\begin{array}{c}\text { specific heat } \mathrm{C} \\
\text { cal/cm.s }{ }^{\circ} \mathrm{C}\end{array}$ & \multicolumn{4}{|c|}{0.12} \\
\hline
\end{tabular}

TABLE I THERMAL PARAMETER ATTRIBUTE TABLE OF 1CR18NI9TI

TABLE II LASER DRILLING PARAMETERS

\begin{tabular}{|c|c|c|}
\hline $\begin{array}{c}\text { Drilling } \\
\text { parameter }\end{array}$ & $\begin{array}{c}\text { The first set of } \\
\text { parameters }\end{array}$ & $\begin{array}{c}\text { The second set of } \\
\text { parameters }\end{array}$ \\
\hline $\begin{array}{c}\text { Laser energy } \mathrm{J} \\
\text { Laser power } \\
\text { density }\end{array}$ & $6 \times 10^{7} \mathrm{~W} / \mathrm{cm}^{2}$ & $2 \times 10^{8} \mathrm{~W} / \mathrm{cm}^{2}$ \\
\hline Pulse width & $0.5 \mathrm{~ms}$ & $0.05 \mathrm{~ms}$ \\
\hline frequency & $50 \mathrm{~Hz}$ & $200 \mathrm{~Hz}$ \\
\hline Spot size & $0.2 \mathrm{~mm}$ & $0.2 \mathrm{~mm}$ \\
\hline
\end{tabular}

It is a simulation figure using the first set of parameters for laser drilling calculation of the temperature field in Figure 2 and Figure 3. It is only $0.3 \mathrm{~ms}$ for the node's temperature up to $2000^{\circ} \mathrm{C}$ when the material begins to melt and then vaporize on the laser spot center at the material top surface in Figure 2. It indicates the temperature field distribution with the inner workpiece in the laser drilling process in each period in Figure 3 (a) $~ 3$ (c). It would be jetted outside with the hole luminal pressure difference when exceed the material melting and boiling point of this material. Then it can remove the material and achieve a certain depth and diameter hole. With the continuation of the time, the material absorbs light energy and passes the heat into the inner material with the way of heat energy from the figure. The diameter and depth of the hole increase gradually. The thermal zone of the temperature field is small.

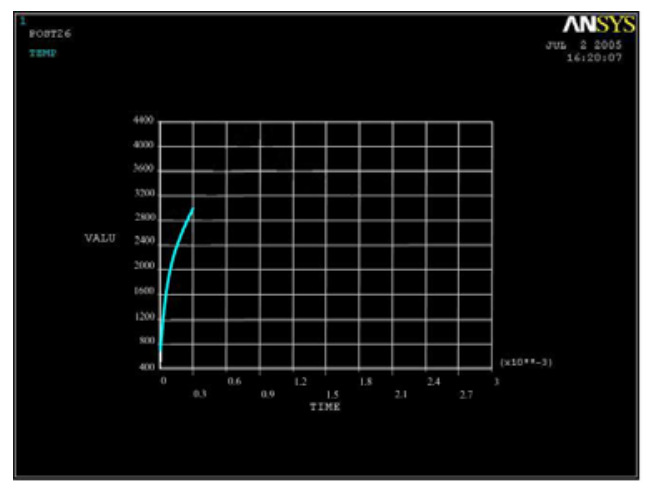

Figure2. change curve of laser spot center node temperature 


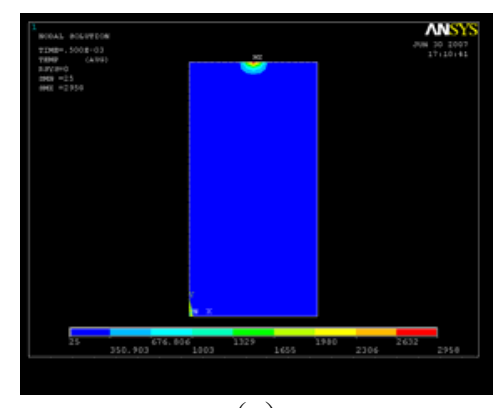

(a)

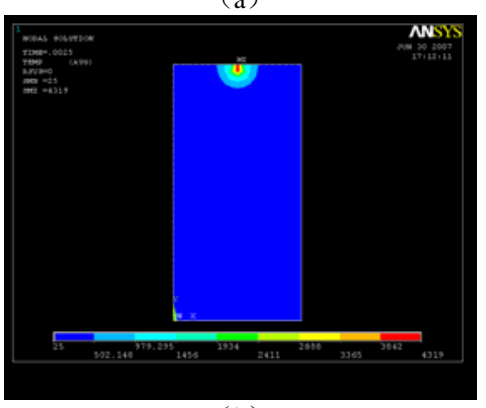

(b)

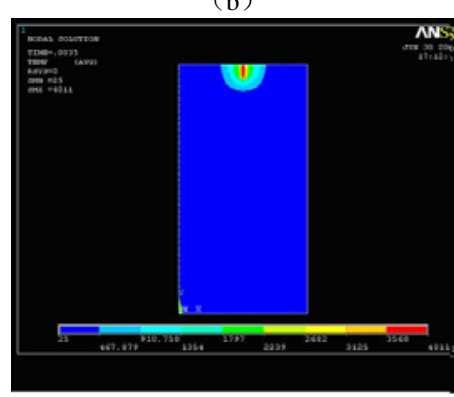

(c)

Figure3. the temperature field picture of laser drilling

The gradient map in Figure 4 is the temperature distribution of drilling simulation calculated of stainless steel 1Cr18Ni9Ti by using the two sets of parameters in Table 2 . The curve in Figure 5 is the surface material temperature distribution of the drilling simulation by using of two sets of parameters. It can be seen from the figure:

(1) The center of temperature field is higher and the vaporization of materials is more fully and the hole of depth is deeper in Figure 4 (b).

(2) The temperature distribution is more uniform. It can ensure the shape of the drilling and reduce the taper of the hole in Figure 4 (b).

(3)The size of temperature field distribution is about $0.25 \mathrm{~mm}$ in Figure 5 (a). The thermal zone is smaller in Figure 5 (b). The size of the distribution range of the temperature field is almost equal to the spot size (about $0.2 \mathrm{~mm}$ ).

It is available to get smaller aperture and better quality holes in the laser drilling process by using higher peak power and pulse width of the laser through the above calculation result of the temperature field.

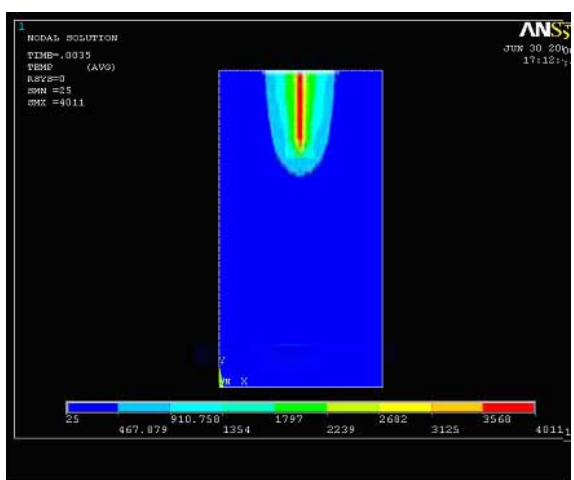

(a) The first set of parameters

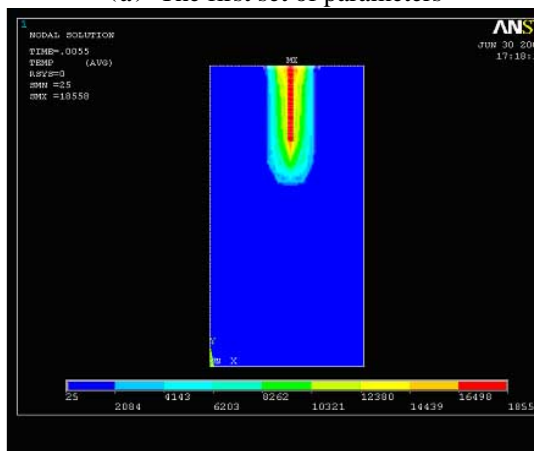

(b) The second set of parameters

Figure4. different parameters of laser drilling temperature field analysis

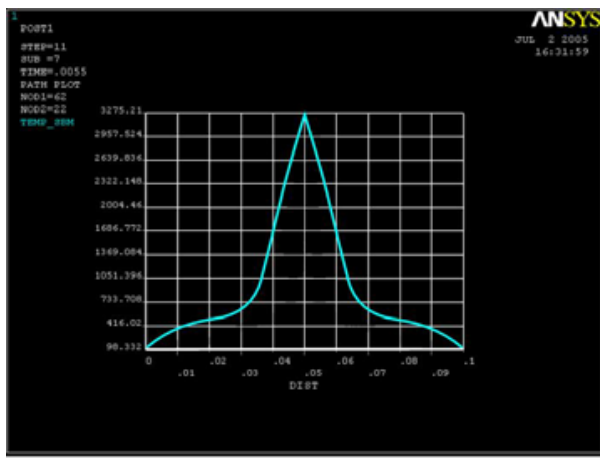

(a) The first set of parameters

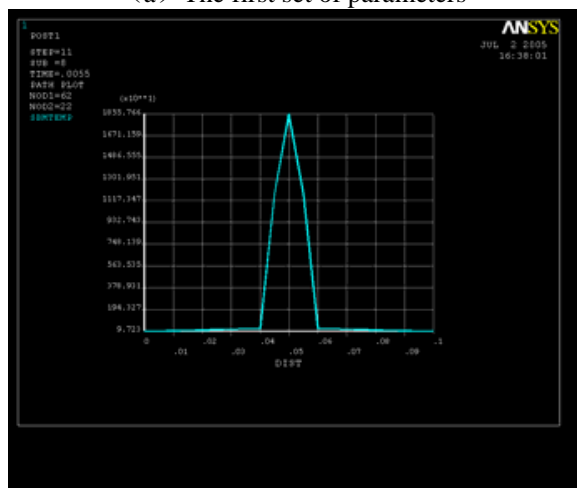

(b) The second set of parameters

Figure5. different parameters of the surface material temperature distribution curve

The curve indicates that the hole of depth and diameter changes over time by using the group 2 parameters in Figure 6 . 
It can be seen that the depth and size of the hole in the initial stage of laser irradiation are greatly increased with the extension of the time. The increase of the hole depth and size is significantly reduced from the measured curve in the figure. The reduction of increasing speed of hole depth is due to the increasing depth of holes and continuation of the time of drilling. The occurrence of defocusing and plasma shielding of laser are made the actual laser energy to reduce. In the later part of the drilling, the pore size is almost unchanged or even be maintained at a constant value. The heat transmits to the inner material with the process of drilling. The laser has a major effect at the bottom of the hole when the processing is mainly to remove the material and thus the quantity of the hole change varies small.

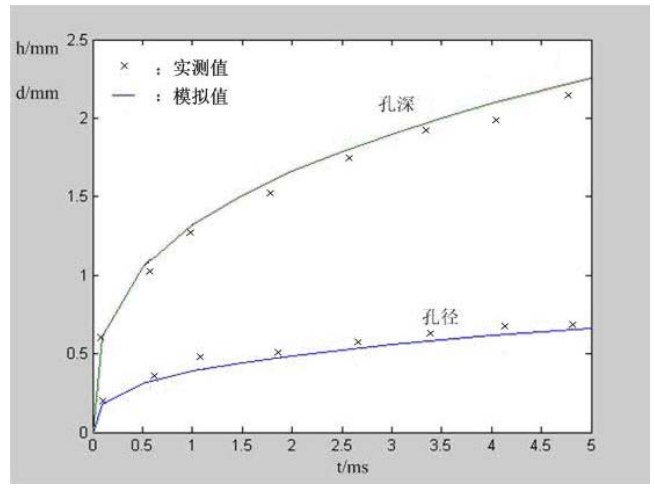

Figure6. The curve of hole depth, pore size change with time

There are some errors between the simulated and measured values which can be seen from the use of ANSYS software simulation.The simulation value of the hole depth is greater than the measured value which is ignored the defocus and plasma during the simulation of laser energy. The smaller size of the hole is due to the gas-liquid mixture spray shooting out the hole wall erosion and there is still a small part of the energy in the hole wall during the process.

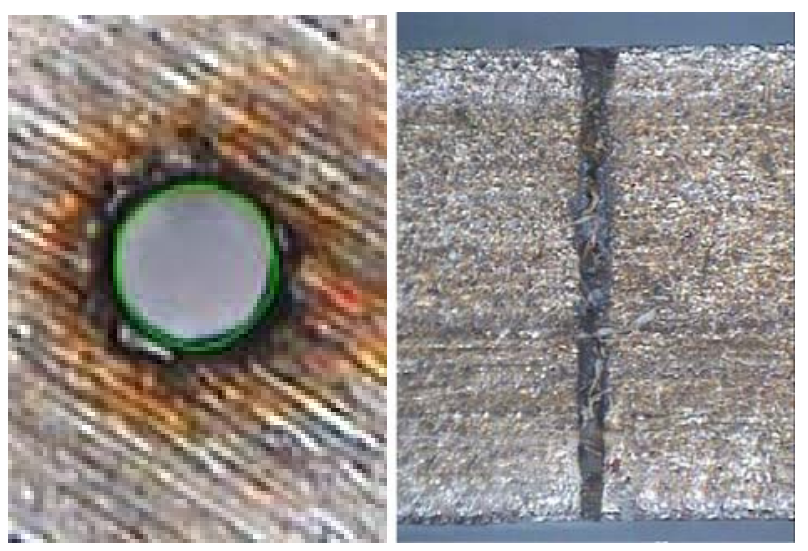

Figure7. Photo of laser drilling

Figure7 is the photo of laser drilling. The drilling center of the workpiece is the origin center. It can be seen the values compared A $(2,0), \mathrm{B}(1.5,0), \mathrm{C}(1,0)$ three-point temperature measured with simulation as Figure 8 below. The temperature sensors used in experiment produced by Aerospace Oriental
Co., Ltd. in Beijing. The measurement range is $0 \sim 600{ }^{\circ} \mathrm{C}$.The measurement accuracy is $K \pm 0.75{ }^{\circ} \mathrm{C}$ which can be met the measurement requirements. It is consistent with the measured and simulated values which verifies the correctness of the temperature field calculation from the figure.

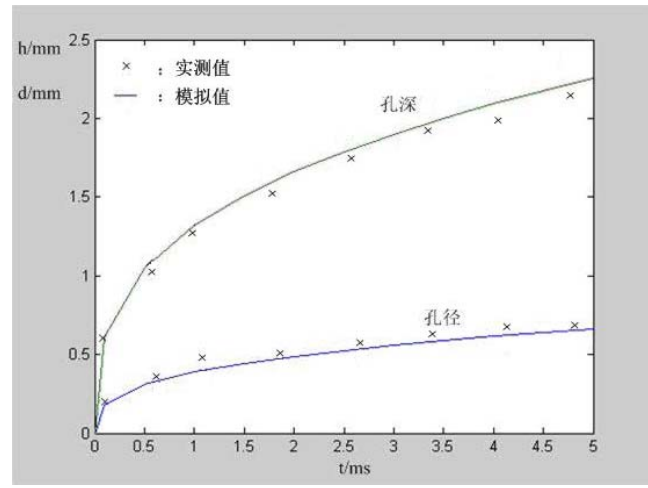

Figure8. Comparison of the simulated changes and measured values

\section{CONCLUSION}

1. A Laser drilling thermodynamic model has been built. It is determined the appropriate boundary and initial condition which is based on the actual environment of the laser drilling. It is corresponded the proposed model with the actual processing conditions which helps to improve the precision and accuracy of the solver of the laser drilling temperature field.

2. The temperature field of laser drilling has been simulated by using APDL language of ANSYS software from which can get the temperature field distribution figure of the material in the drilling process. It laid the foundation for drilling parameters optimal selection and analysis of drilling quality.

3. The relationship curve between the depth and size and time of the pore has been got. The causes of errors have been analyzed.

4. The measured values match with the simulated values which is based on comparing the simulated values with measured values of temperature in the laser drilling process.

\section{REFERENCES}

[1] Gao Ji, Cao Guoqiang micro-hole technology and its development status of the special processing [J]. Mechanical design and manufacturing .2005.07:169-171

[2] Zuo Tiechuan. Modern laser manufacturing and its effect on the importance of developing national economy [J]. Xiangshan Science Conference Proceedings .2003.1-6

[3] Tang Xinglun ANSYS engineering applications tutorial. Thermal and electromagnetics papers [M]. China Railway Publishing House .2003.77-78

[4] S. Tosto. Modeling and computer simulation of pulsed-laser-induced ablation. Applied Physics A: Materials Science \& Processing. 2002.68 (4) $.439-446$

[5] Yao Zhongpeng, Wang Ruijun heat transfer [M] Beijing: Beijing Institute of Technology Press,1995.17 -20 